\title{
AEROMAGNETIC MAP OF THE ABERDEEN QUADRANGLE GRAYS HARBOR AND PACIFIC COUNTIES, WASHINGTON By
}

John R. Henderson, Natalie S. Tyson, Ernest F. MoGowan and others

GEOPHYSICAL INVESTIGATIONS

MAP GP 177

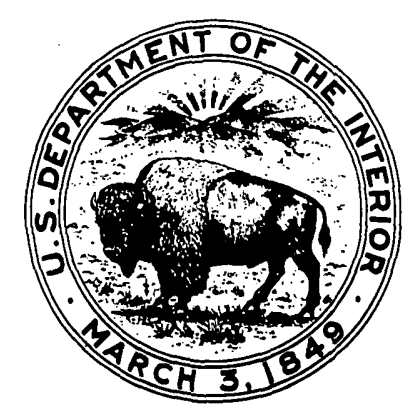

